\title{
EFFECTS OF FEMALE MANAGERS' LEADERSHIP ON TEAMWORK AND ORGANIZATIONAL PERFORMANCE IN CATERING INDUSTRY
}

\author{
Monica Shu-Fen WU \\ Department of Hospitality Management, Wu Feng University, 117, Sec 2, Chiankuo Rd., \\ Minhsiung, Chiayi County 62153, Taiwan, R.O.C.E-mail:monicawu30@hotmail.com
}

\begin{abstract}
The promotion of educational standards and the rising independent awareness of females, females are gradually taking a place in the employment market. Industrial structure evolution and social transformation have the societies in Taiwan change from traditional manufacturing to hi-tech, information, and food service industries. Demands for human resources therefore become different from the past that lots of employment opportunities were indirectly created for females. Regarding the labor participation rate, the increasing female engagement in workplaces has enhanced the generation of female leadership. The unique female personality traits could assist female managers in forming unique management styles in business management. Aiming at Wowprime, total 650 copies of questionnaires are distributed, and 477 valid copies are retrieved, with the retrieval rate $73 \%$. The results conclude 1. positive effects of leadership on teamwork, 2. positive effects of teamwork on organizational performance, and 3. positive effects of leadership on organizational performance. The results are expected to help the leadership of female managers in catering industry.
\end{abstract}

Keywords: catering industry, female manager, leadership, teamwork, organizational performance

\section{RESEARCH BACKGROUND}

The development of social economy has hastened the movement in the knowledge era, changed corporate environments, and increased highly-educated female population. Especially, female labor participation rate is obviously higher than male one and females eventually could compete and cooperate with males in workplaces. The increasing proportion of female engagement in workplaces has enhanced the generation of female leadership that more female managers are required in the new century (Lin, Yang and Zheng 2014). It is not simply the efforts 
of females, but the societies and enterprises requiring new elements and new vision from females. Females present unique personality traits to help female managers form unique management styles in the business management. It also has female groups become an essential power in the social development. Issues on female workers therefore become primary. In the gender equality era, the increasing female leaders have the leadership characteristics, core capability, and leadership effectiveness be worthy of further discussions.

Leadership is changing in the knowledge worker era in the $21^{\text {st }}$ century, when a lot of females engage in workplaces. The promotion of educational standards and the rising female independent awareness allow females taking a place in the employment market. Industrial structure evolution and social transformation also change the societies in Taiwan from traditional manufacturing into hi-tech, information industry, and food service industries. Most employees engaging in catering industry, including supervisors and professional and technical staff, with usual or temporary positions, are female. Demands for human resources therefore are different from those in the past that lots of employment opportunities are indirectly created for females. In the diverse societies and rapidly changing environments, an individual or an organization has to have an insight into the trend and proper responses for the sustainable development of an organization. When an organization faces sudden and rapid changes of environmental networks, various internal and external factors in the successful organizational management are required. "Team" could provide several combinations of skills, avoid the organization becoming a set composed of large amount of individuals without organizational activities, contribute to the organization, and create excellent organizational performance in certain time limit. When workplaces move towards work specialization, a lot of projects are completed depending on the mass power. Teamwork contains the behaviors of establishing harmonious relationship, agreeing with others, approving others' contribution, actively achieving team goals, and actively sharing information with members who are in difficulty. Up to $90 \%$ enterprises therefore consider Teamwork as the most important core capability of employees. Teamwork is listed on top three core capabilities in both technology and service industries (Belinskaja and Paulienè 2014).

\section{LITERATURE REVIEW}

\subsection{Leadership}

A leader plays a critical role in an organization. Successful leadership is not the sole element for organizational success, while it can decide the organizational performance (Farzin et al. 2012). Leadership is the presentation of leader be- 
haviors that the features of a leader are presented through the leadership, while leadership cannot be rapidly formed or changed (Groves and LaRocca 2011). Confirming organizational vision, establishing organizational directions, and having the followers understand and encouraging their movement towards the goal are the primary issues for a leader. Judeh (2012) explained leadership as the interactive relationship between a leader and the followers; under restricted resources, advocacy and persuasion were applied to generate consensus among members combining together and trusting each other to cooperatively achieve specific objectives. Liu et al. (2013) further pointed out leadership as a manager, under specific situations, affecting the behaviors of an individual or a group of people to approach the goal preset by certain groups through the interpersonal relationship activities (Belinskaja and Paulienè 2014). Robbins and Judge (2011) indicated that leadership was an influencing process, and the differences between a leader and a manager appeared on the encouragement and the thinking and behavior model. Since leadership merely referred to the process to influence others completing the objectives, a leader in an organization therefore was not necessarily a manager, while a manager would be a leader.

This study refers to the five major elements of leadership proposed by Pinho et al. (2014). (1) Model the way. A leader has to clarify personal and organizational value, present real self, and combine common value and behaviors of the organization to be a good example of the subordinates. (2) Inspire a shared vision. A leader must present farsightedness, be clear of future demands, animate the organizational vision, and strive for the support of organizational members with the idea and appeal of a common destiny. (3) Challenge the process. A leader actively looks for opportunities, is willing to try errors, presents adventurous spirits, and develops the organization with innovation. (4) Enable others to act. A leader creates the atmosphere of organizational trust, thoroughly empowers the subordinates, trains the competence and self-confidence, and cultivates the spirit of teamwork to cooperatively complete organizational objectives. (5) Encourage the heart. It refers to drawing a clear standard for measuring the performance, approving personal contribution of subordinates, creating the spirit of social communities, and publicly appraising value and victory.

\subsection{Teamwork}

Bowler et al. (2010) defined that a team was consisted of two or more members who mutually coordinated with each other to complete the common task. Ferreira and Armagan (2011) indicated that a team should not simply stress on the achievement of overall objectives, but should emphasize the dependence and mu- 
tual commitment among members. Hartnell et al. (2011) regarded a team being composed of few people with complementary skills; such people agreed with a common objective and the process for which they would undertake the responsibilities. Cooperation referred to the common efforts under the same objective, and teamwork was formed by coordination, communication, purpose, relationship, trust, and structure in a team. Successful cooperation was to achieve the expected results and performance through the efforts of team members (Kaufman 2011). McShane and Von Glinow (2013) considered that it was important to share information and satisfy both parties and to integrate personal opinions from other's opinions for the cooperation of solution plans beneficial to both parties. In this case, cooperation contained the common actions, objectives, and value of both parties, and both parties were dependent. Peterson et al. (2012) regarded cooperation as both parties establishing and managing the relationship through cognition and expectation and achieving the ideal in the working or task completing processes. Robbins and Judge (2014) pointed out cooperation as two or more individuals acting coordinately to achieve the common objective in order to enhance the results beneficial to the person and the others. Cooperation was opposite to competition. However, competition was not completely negative; it was the motivation to enhance cooperation among members and to combine individual power to consist the common cooperation of a team, allowing the organization possessing powerful competitiveness. Yuki (2006) mentioned the elements of teamwork as emphasizing common interests and value and encouraging social activities and expected to enhance cooperation and increase the cooperative opportunities by holding some rituals and ceremonies. Furthermore, the overall objective was to enhance the common objective in teamwork.

The dimensions of communication and coordination, concern and support, and assistance for teamwork proposed by Shanker and Sayeed (2012) are adopted in this study.

(1) Communication and coordination

Teamwork is consisted of certain tasks, aiming to cooperatively achieve the objective for certain rewards.

(2) Concern and support

Maintaining interpersonal relationship is particularly important in the teamwork process, as interpersonal support and assistance would enhance favorable interpersonal relationship for the team cooperation.

(3) Assistance

Teamwork requires trust, confidentiality, mutual respect, and cherish of mutual contributions among team members; information exchange and mutual benefits among team members, making each member equal and share and take responsibilities of objectives and results. 


\subsection{Organizational performance}

Dessler (2010) regarded organizational performance as the degree of an individual helping the organization complete the objectives as well as the behaviors to achieve the expected, regulated, or required as a formal role of the organization. Gary (2011) pointed out organizational performance as the quality and quantity of an individual or an organization achieving the tasks as well as a manager achieving the tasks on the position. Hinson and Abdulai (2011) covered effectiveness, efficiency, and participant satisfaction in organizational performance. Most domestic and international researchers considered organizational performance as the degree of an organization achieving the objectives that the operation result of the organization was a comprehensive concept (Kefela 2012). Nevertheless, the evaluation of organizational performance changed with research aspects and the measurement appeared distinct principles and differences. Mohamed and Anisa (2012) proposed the conceptualization of performance, containing financial performance, business performance, and organization effectiveness. NaranjoValencia et al. (2011) proposed balanced score cards (BSC), which contained the dimensions of financial, customer, internal business processes, and learning and growth to measure the overall performance.

Trifan et al. (2012) suggested Job Satisfaction, Organizational Objective, and Job Performance as the measuring indicators of Organizational Performance. Such indicators are covered in this study.

(1) Job satisfaction

Piccolo et al. (2010) first proposed job satisfaction and regarded it as subjective satisfaction of employees with the working environment and the work psychologically and physiologically. They considered job satisfaction as the degree of employees liking or disliking the work; and, job satisfaction appeared when the work characteristics were suitable for the worker's expectation.

(2) Organizational objective

Objectives refer to the standards of a job or a plan as well as an accurate, specific, and common benchmark coming from internal power.

(3) Job performance

Robbins and Judge (2014) regarded job performance as the "quality and quantity" of an individual or a group achieving the tasks. Trifan et al. (2012) pointed out job performance as an individual, as an organizational member, completing the expected, regulated, or requested requirements as a formal role. 


\subsection{Research on the correlations among leadership, teamwork and organizational performance}

Being a top-down interactive relationship, leadership is also an issue in management to enhance the cooperation and communication among team members through a favorable interactive environment in order to further induce team members achieving team objectives. Domestic and international research on leadership and teamwork are summarized as following. Jiao et al. (2011) mentioned the positive correlation between leadership styles and teamwork to further enhance the innovation of a team. Robbins and Judge (2011) pointed out the significant effects of a coach's leadership on the players' team objectives, cooperation, and interpersonal relationship. Tsai et al. (2011) proposed the remarkable effects of a manager's leadership styles on team climate. Valentine et al. (2011) indicated that high-concern and high-system leadership styles of managers appeared notable effects on the performance of R\&D teams. Most researchers supported the direct or indirect effects of leadership on teamwork. It is inferred in this study that significantly positive effects appear between leadership and teamwork. The following hypothesis is therefore developed.

H1: Leadership presents positive effects on teamwork.

Robbins and Judge (2014) also regarded the mutual cooperation in a team being able to reduce competition among individuals. Tsai (2011) considered that the application of teamwork could present better productivity, more efficiently utilize resources, and more effectively solve problems. In other words, a team was generated by the mutual cooperation among the members to reduce individual competition and enhance the productivity by effectively applying limited resources. Hinson and Abdulai (2011) argued the positive effects of teamwork on team performance and job satisfaction. Groves and LaRocca (2011) pointed out the partially direct and positive effects of team member interaction on team effectiveness. Judeh (2012) mentioned that teamwork could effectively enhance work effectiveness by reinforcing the education and improving working environments. Accordingly, the following hypothesis is developed.

H2: Teamwork reveals positive effects on organizational performance.

Leadership is a key factor in the effective application of human resources (Voon et al. 2011); efficient leadership could create the vision of an organization, develop strategies to achieve organizational objectives, and encourage the employees executing such strategies for organizational benefits. Tsai (2011) pointed out the remarkably positive correlations between charismatic, considerate, and inspiring leadership on individual job satisfaction and belongingness, productivity and 
efficiency objectives, and group relationship in the organizational performance objectives. Mohamed and Anisa (2012) discussed the significant effects of leadership on organizational performance. Kefela (2012) mentioned the notable correlations between leadership styles and organizational performance. Trifan et al. (2012) showed the significantly positive effects of transformational leadership on leadership effectiveness. The remarkably positive effects of leadership on organizational performance are inferred in this study that the following hypothesis is developed.

H3: Leadership shows positive effects on organizational performance.

\section{DESIGN OF RESEARCH METHOD}

\subsection{Operational definition of variable and the measurement}

(1) Leadership

Leadership contains the dimensions of model the way, inspire a shared vision, challenge the process, enable others to act, and encourage the heart. The scale is referred to Pinho et al. (2014). The overall reliability coefficients reveal 0.82 , $0.80,0.88,0.90$, and 0.83 for model the way, inspire a shared vision, challenge the process, enable others to act, and encourage the heart, respectively.

(2) Teamwork

The teamwork scale is referred to Shanker and Sayeed (2012). The overall reliability coefficients for communication and coordination, concern and support, and assistance appear $0.85,0.81$, and 0.89 , respectively.

(3) Organizational performance

Organizational performance, referring to Trifan et al. (2012), is divided into the dimensions of job satisfaction, organizational objective, and job performance. The overall reliability coefficients present job satisfaction 0.91 , organizational objective 0.78 , and job performance 0.87 .

\subsection{Research subject}

Aiming at Wowprime, the female managers are distributed the questionnaire in this study. Established in 1993, Wowprime has created 13 brands, including Wang Steak, TASTy, Tokiya, Yakiyan, Giguo, Ikki, Chamonix, Pinnada, 12hotpot, Sufood, Fmonn Coffee, hot7, and ita, and currently possesses 307 chain stores in Taiwan. With excellent corporate culture and chain-store management systems, Wowprime insists on the management principle of S.T.I.S. 1. SINCERITY. 
Sincerity is the first task to face people and affairs, including the company, the colleagues, the manufacturers, the customers, and the family members. 2. TEAMWORK. Teamwork, the spirit of a team, could develop multiple team power. It is believed that the potential of each person could be developed to the ultimate under the group encouragement. 3. INNOVATION. Creation is unlimited. People should not hold on old customers, but dare to challenge the tradition, and not be superstitious and old-fashioned. Any decisions could be analyzed with objective numbers. 4. SATISFACTION. Anything done should satisfy the customers, the company, the family members, and everyone surrounding. Certainly, selfsatisfaction, not self-contented, but self-effacing, is important. Total 650 copies of questionnaires are distributed, and 477 valid copies are retrieved, with the retrieval rate $73 \%$.

\subsection{Reliability and validity analyses}

The reliability of the research dimensions achieve up to 0.7 , showing the high reliability. The construct validity is analyzed with Confirmatory Factor Analysis, and the favorable convergent validity and construct validity are shown in Table 1.

Table 1. Confirmatory factor

\begin{tabular}{l|l|l}
\hline Dimension & Overall fit & Analysis \\
\hline Leadership & $\mathrm{X} 2=0(\mathrm{P}<0.001) ; \mathrm{DF}=0 ; \mathrm{GFI}=1.00 ; \mathrm{CFI}=1.00$ & excellent overall model fit \\
\hline Teamwork & $\mathrm{X} 2=0(\mathrm{P}<0.001) ; \mathrm{DF}=0 ; \mathrm{GFI}=1.00 ; \mathrm{CFI}=1.00$ & excellent overall model fit \\
\hline $\begin{array}{l}\text { Organizational } \\
\text { performance }\end{array}$ & $\mathrm{X} 2=0(\mathrm{P}<0.001) ; \mathrm{DF}=0 ; \mathrm{GFI}=1.00 ; \mathrm{CFI}=1.00$ & excellent overall model fit \\
\hline
\end{tabular}

\section{ANALYSIS RESULT}

\subsection{Correlation analysis}

From Table 2, remarkable correlations appear among leadership, teamwork, and organizational performance. The result shows the possibility of multicollinearity. Niehoff and Moorman (1993) suggested that Nested Model Analysis could be used for solving such a problem. The notable correlations among dimensions also reveal the matching information with the research hypotheses. 
Table 2. Correlation analysis

\begin{tabular}{l|c|c|c|c}
\hline Dimension & $\alpha$ & Leadership & Teamwork & Organizational performance \\
\hline Leadership & 0.85 & & & \\
\hline Teamwork & 0.87 & $0.31^{* *}$ & & \\
\hline Organizational performance & 0.82 & $0.24^{*}$ & $0.38^{* *}$ & \\
\hline
\end{tabular}

Note: $*$ stands for $\mathrm{p}<0.05, * *$ stands for $\mathrm{p}<0.01$

\subsection{Theoretical model}

The research results are shown in the following figure. The path coefficients reaching the significance are shown with solid lines, while the ones not reaching the significance are shown with dotted lines in this study. It is obvious that all of the path coefficients achieve the convergent validity, conforming to the basic requirements for the model analysis. According to the goodness-of-fit indices, GFI $=0.944$, AGFI $=0.921$, RMSEA $=0.03$, and CFI $=0.983$, the model fit is verified, revealing the research model conforming to the theory and being valid.

\subsection{Discussion of research hypothesis}

With a nested model, the research hypotheses are tested with chi-square. Since each nested model shows the difference of a degree of freedom, the deduction of the chi-square value between the nested model and the theoretical model appearing 0 reveal the significant path coefficient. The research result shows the model achieving the significant. The Nested Model Analysis is shown in Table 3, and the hypothesis verification is shown in Table 4.

Table 3. Nested Model Analysis

\begin{tabular}{l|c|c|c|c|c}
\hline Model & $\chi^{2}$ & $\Delta \chi^{2}$ & GFI & CFI & RMSEA \\
\hline Theoretical model & 288.74 & & 0.944 & 0.983 & 0.03 \\
\hline $\begin{array}{l}\text { Model 1: hypothesis } \\
\text { verification }\end{array}$ & 292.40 & $3.66^{*}$ & 0.944 & 0.983 & 0.03 \\
\hline $\begin{array}{l}\text { Model 2: hypothesis } \\
\text { verification }\end{array}$ & 298.12 & $5.72^{*}$ & 0.944 & 0.983 & 0.03 \\
\hline $\begin{array}{l}\text { Model 3: hypothesis } \\
\text { verification }\end{array}$ & 302.51 & $4.39^{*}$ & 0.944 & 0.983 & 0.03 \\
\hline
\end{tabular}

Note: $*$ stands for $\mathrm{p}<0.05$ 
Table 4. Hypothesis verification

\begin{tabular}{l|c|c|c|c}
\hline Hypothesis & Correlation & Empirical result & $\mathrm{P}$ & Result \\
\hline Hypothesis 1 & + & 0.389 & 0.00 & supported \\
\hline Hypothesis 2 & + & 0.367 & 0.00 & supported \\
\hline Hypothesis 3 & + & 0.316 & 0.00 & supported \\
\hline
\end{tabular}

\section{CONCLUSION}

From the research results, there are notable correlations among leadership, teamwork, and organizational performance. In addition to the effects of female managers' leadership on the cognition and perception of teamwork in catering industry, the effects of teamwork on organizational performance are also investigated. Meanwhile, the research results could be the reference for managers in catering industry and successive researchers. Human assets are primary in catering industry. After recruiting excellent workers, it is expected to complete the optimal organizational objective and pursue the performance. In the highly competitive environments, organizational performance and competitive advantages of an enterprise rely on the employee behaviors in order to achieve sustainable survival. It requires an adjustment period for the agreement in a team; especially, when employees encounter frustration and bottleneck in the challenge of tasks or the interpersonal interaction, the support from other members for the mature and stable organizational objective could shape the organizational culture and enhance the competitiveness.

Female managers in catering industry should clearly set the objectives and value so that the employees could follow the standards to engage in the work, cultivate the idea of team destiny, appeal to the common vision, and cooperatively work for the objectives. Besides, the employees are encouraged to give opinions and feedback, concerned the working situations, and publicly appraised so as to enhance the self-value to work hard for the organizational performance.

\section{SUGGESTION}

From the research results and findings, practical suggestions are further proposed.

1. Potential employee selection has been an important function on human resource management. Selecting correct and excellent talents could promote the operation of an enterprise and an organization in the future development. The effect of strong leadership motivation lies in the leader being actively playing 
the role. Strong leadership motivation refers to the motivation to "do things well"; female leaders without strong leadership motivation would passively accept the role or play the role with certain stimulation. In this case, female leaders with strong leadership motivation and excellent performance would actively strive for opportunities, while those without strong leadership motivation would wait for the stimulation from the environment or other people. Self-concept, personality traits, and motivation (i.e. attitudes) are implicit, uneasily trained and developed that selecting potential employees with motivation and traits is important.

2. Food service businesses could stress on the competence cultivation of female leaders in the training process. Besides, resources could be provided for female leaders acquiring necessary knowledge and reinforcing the intention for further study; and, professional courses, such as catering related courses, round table leadership, communication coordination training, and promotion education in colleges, are arranged in order to promote the professional capabilities of female leaders in catering industry as well as cultivate the competence.

3. Female leaders need to make progress and constantly make efforts and progress to develop the strength. Efforts are a kind of lifelong learning. A manager, who could constantly absorb relevant professional knowledge, actively find out problems, and try to solve problems as well as carefully make judgment according to current situations, could effectively encourage the employees engaging in the work. In consideration of the importance of job engagement, female leaders in catering industry are suggested to engage in concerning the employees, change employees' attitudes and behaviors through leadership and management, establish harmony and communication for interpersonal relationship and information shared environments, enhance the trust among employees, and apply diverse encouragement to enhance employees' work motivation so as to create higher leadership effectiveness and further promote employees' job engagement.

\section{REFERENCES}

Belinskaja, L. and Paulienè, R. (2014). Overview of the Current Leadership Theories: What it Means to Lead?, Proceeding of the 8th International Scientific Conference in Business and Management, May 15-16, in Vilnius, Lithuania, 254-268

Bellou, V. (2010). Organizational culture as a predictor of job satisfaction: the role of gender and age. Career Development International, 15(1), 4-19.

Bowler, W.M., Halbesleben, J.R. and Paul, J.R. (2010). If you're close with the leader, you must be a brownnose: The role of leader member relationships in follower, leader, and coworker attributions of organizational citizenship behavior motives. Human Resource Management Review, 20, 309-316. 
Dessler, G. (2010). Human Resource Management, 12th ed. New Jersey: Prentice-Hall.

Farzin, F., Azadehdel, M., Rezaei-Dizgah, M. and Nezhadi-Jirdehi, M. (2012). Organizational citizenship behavior: The role of organizational justice and leader-member exchange. Institute of Interdisciplinary Business Research, 3(9), 893-903.

Ferreira, M. and Armagan, S. (2011). Using social networks theory as a complementary perspective to the study of organizational change. Brazilian Administration Review, 8(2), 168-184.

Gary, S. (2011). Key factors for successfully implementing and sustaining quality improvement in K-12 education. The Journal for Quality and Participation, 33(4), 17-20.

Groves, K.S. and LaRocca, M.A. (2011). An empirical study of leader ethical values, transformational and transactional leadership, and follower attitudes toward corporate social responsibility. Journal of Business Ethics, 103, 511-528.

Hartnell, C.A., Ou, A.Y. and Kinicki, A. (2011). Organizational culture and organizational effectiveness: a meta-analytic investigation of the competing values framework's theoretical suppositions. Journal of Applied Psychology, 96(4), 677.

Hinson, R.E. and Abdulai, M. (2011). Qualitative insights into market orientation in small Ghanaian businesses. International Journal of Marketing Studies, 3(1), 35-44.

Jiao, C., Richards, D.A. and Zhang, K. (2011). Leadership and organizational citizenship behavior: OCB-Specific Meanings as Mediators. J Bus Psychol, 26, 11-25.

Judeh, M. (2012). Assessing the influence of job characteristics and self-efficacy on job performance: A structural equation modeling analysis. European Journal of Social Sciences, 28, $355-365$.

Kaufman, B. (2011). Leadership strategies: build your sphere of influence. Business Strategy Series, 12(6), 315-320.

Kefela, G.T. (2012). Organizational culture in leadership and management. PM World Today, 14(1), $1-12$.

Lin, W., Yang, Y. and Zheng, Q. (2014). Influence of professional women's work and family conflict on the turnover intention in cultural enterprises - based on the mediating effect of managerial support and organizational family support. Acta Oeconomica, 64(Supplement 2), 213-227.

Liu, J., Kwan, H.K., Fu, P.P. and Mao, Y. (2013). Ethical leadership and job performance in China: The roles of workplace friendships and traditionality. Journal of Occupational and Organizational Psychology, 86(4), 564-584.

McShane, S. and Von Glinow, M. (2013). M: Organizational Behavior. McGraw-Hill Higher Education.

Mohamed, M.S. and Anisa, H. (2012). Relationship between organizational commitment and organizational citizenship behavior. The IUP of Organizational Behavior, 6(3), 7-22.

Naranjo-Valencia, J.C., Jimenez-Jimenez, D. and Sanz-Valle, R. (2011). Innovation or imitation? The role of organizational culture. Management Decision, 49(1), 55-72.

Niehoff, B.P. and Moorman, R.H. (1993). Justice as a mediator between methods of monitoring and organizational citizenship behavior. Academy of Management Journal, 36, 527-556.

Peterson, S.J., Walumbwa, F.O., Avolio, B.J. and Hannah, S.T. (2012). The relationship between authentic leadership and follower job performance: The mediating role of follower positivity in extreme contexts. The Leadership Quarterly, 23(3), 502-516.

Piccolo, R., Greenbaum, R., Den Hartog, D. and Folger, R. (2010). The relationship between ethical leadership and core job characteristics. Journal of Organizational Behavior, 31, 259-278.

Pinho, J.C., Rodrigues, A.P. and Dibb, S. (2014). The role of corporate culture, market orientation and organisational commitment in organisational performance: The case of non-profit organisations. Journal of Management Development, 33(4), 374-398. 
Robbins, S.P. and Judge, T.A. (2011). Organizational Behavior, 14th ed. New Jersey: Pearson Education.

Robbins, S.P. and Judge, T.A. (2014). Organizational Behavior. Pearson Higher Ed.

Shanker, M. and Sayeed, O.B. (2012). Role of transformational leaders as change agents: Leveraging effects on organizational climate. Indian Journal of Industrial Relations, 47(3), 470-484.

Trifan, E.L., Guica, R.I. and Micu, C.A. (2012). Innovation management and technology transfer within a model of innovation center at the University Politechnica of Bucharest. Problems of Management in the 21st Century, 4, 74-85.

Tsai, C-T.S., Su, C-S. and Cai, Z.C. (2011). Leadership, job satisfaction and service-oriented organizational citizenship behaviors in flight attendants.

Tsai, Y. (2011). Relationship between organizational culture, leadership behavior and job satisfaction. BMC Health Services Research, 11(1), 98.

Valentine, S., Godkin, L., Fleischman, G.M. and Kidwell, R. (2011). Corporate ethical values, group creativity, job satisfaction and turnover intention: The impact of work context on work response. Journal of Business Ethics, 98(3), 353-372.

Voon, M., Lo, M., Ngui, K. and Ayob, N. (2011). The influence of leadership styles on employees' job satisfaction in public sector organization in Malaysia. International Journal of Business, Management and Social Sciences, 2(1), 24-32.

Yuki, G. (2006). Leadership in Organizations (6th ed.). Upper Saddle River, NJ: Pearson Education. 